\title{
Cloud connected smart home gas cylinder platform based wifi control
}

\author{
C. R. Balamurugan, P. Vijayakumar \\ Karpagam College of Engineering, India
}

\section{Article Info}

Article history:

Received Jul 23, 2019

Revised Nov 2, 2019

Accepted Nov 22, 2019

\section{Keywords:}

Cloud

Gas cylinder

Load cell

Safety

Wireless networks

\section{Corresponding Author:}

C. R. Balamurugan,

Karpagam College of Engineering,

Myleripalayam Village, Othakkal Mandapam, Tamil Nadu 641032, India.

Email: hod.eee@kce.ac.in

\begin{abstract}
The aim of this work is to protect our home asserts from any kind of hazards. The proposed work is used to detect the leakage of gas through a gas sensor and measures the weight of cylinder through load cells. The real time data and informations are strored in cloud for further retrival of information in future. Based on weight of the cylinder the amount of gas availibale and due date to change new cylinder may also be known. The survey was made to examine the existing work in security system and its applications.
\end{abstract}

Copyright (c) 2019 Institute of Advanced Engineering and Science. All rights reserved.

\section{INTRODUCTION}

The cylinder usage has increased gradually by all the peoples nowadays. While using first of all the safety is very important. In order to ensure the reliability and safety aspects the proposed work was discussed in this paper. This work will give more important on safety of human beings. Babuprasanth in [1] discussed in detail about the smart gas leakage detection concept in detail. Ruqsar et al [2] suggested elaborately the protection system using advanced technology internet of things. Shopan et al [3] proposed the concept regarding home automation. Through IoT the equipments available in the homecan be easily controlled without any physical contacts. Patil et al [4] discussed about the advancement in the kitchen using internet of things. Pooja et al [5] developed a new system related to home safety using recent technologies like IoT, Wifi and cloud. Santhosh Krishna et al [6] introducted new type of robot that works on the concept of cloud which has wide applications on industry. Ayyar et al [7] suggested the method of protection of cyclinder with the help of cloud technology. Anandhakrishnan et al [8] proposed a new gas monitoring system based on IoT. Sharmain [9] developed a multipath system for wirelesssystem. Nag and Sarvagya [10] discussed about 5G wireless systems. Marokar and Zade [11] discussed about the signal transmission systems.

\section{SOFTWARE USED}

Energia Platform and SWD Debugger are preferred for this work.

\#define BLYNK_PRINT Serial // Comment this out to disable prints and save space \#include 〈SPI.h> \#include <WiFi.h> \#include <BlynkSimpleTI_CC3200_LaunchXL.h〉 \#include <Wire.h> \#include $<$ SimpleTimer.h> \#include "Adafruit_TMP006.h" \#include <Servo.h $>/ *$

*///\#define LOADCELL_CHECK char ssid[] = "hazardsense"; char pass[] = "hazardsense"; char auth[] = "8092655e0a0b4f2b8abf8f2790cb6144"; //student char email_id[] = "mashwini1995@gmail.com"; // user id char vendor_id[] = "mashwini1995@gmail.com"; // vendor id. 


\section{HARDWARE DESCRIPTION}

The precautionary measures are (i) Closes the gas valve (ii) Opens the air ventilation (iii) Shutsoffthe home electricity (iv) to prevent electrical sparks (v) Provides a loud local alarm to alert neighbours (vi) Sends a smart phone alert to the owner (vii) Waits for the gas concentration to return to normal. CC3200, ARM cortex-M4 WIFI Microcontroller. The parts of the hardware are External Flash Memory, LPG gas level sensor, Load cell, 24-bit ADC, Infrared temperature sensor, Fire sensor, AC Relay circuitry, Servomotor, DC fan mechanism, Fire sprinkler DC motor, 6v Battery, Notification LEDs and Loudspeaker.

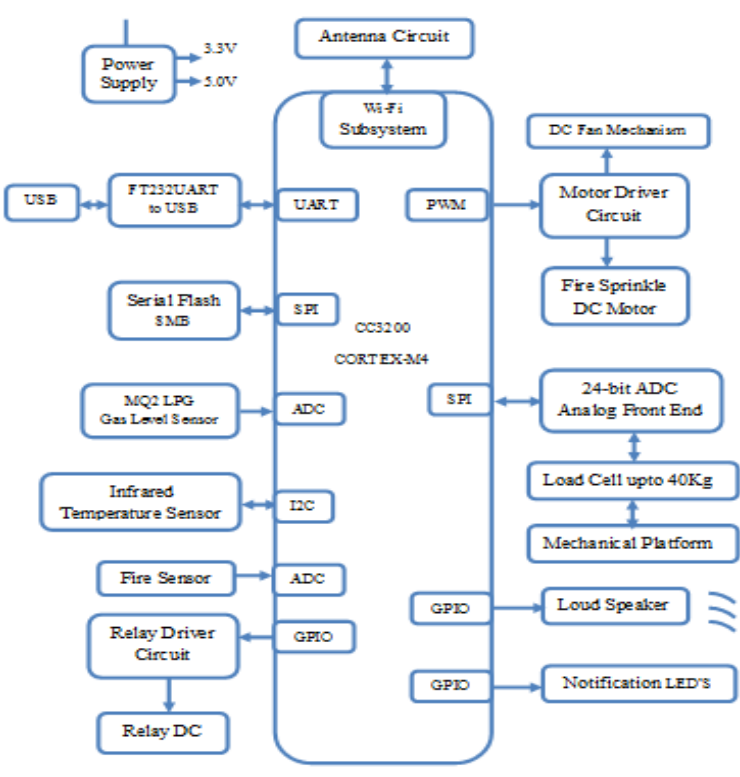

Figure 1. Block diagram

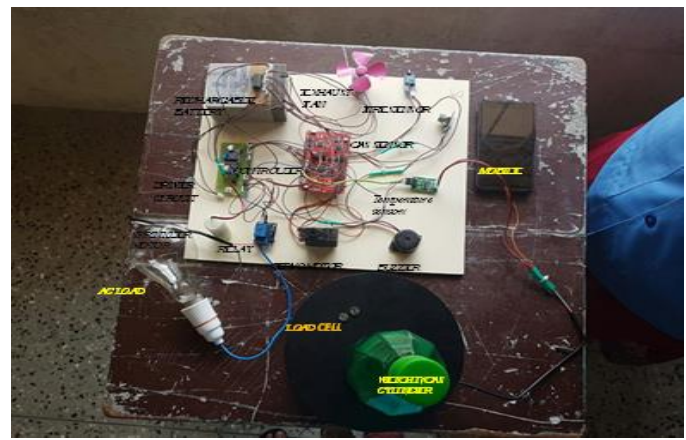

Figure 2. Hardware kit

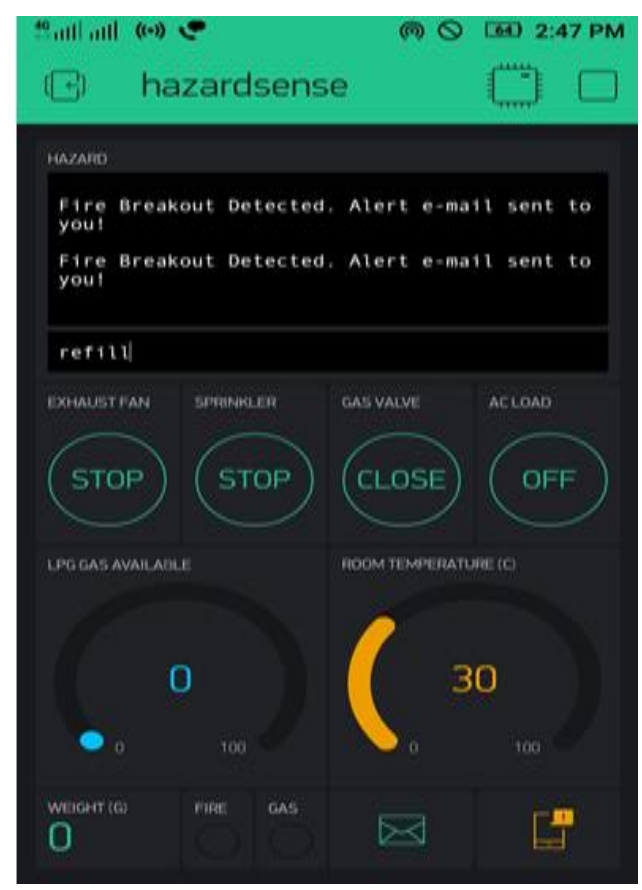

Figure 3. Initial condition

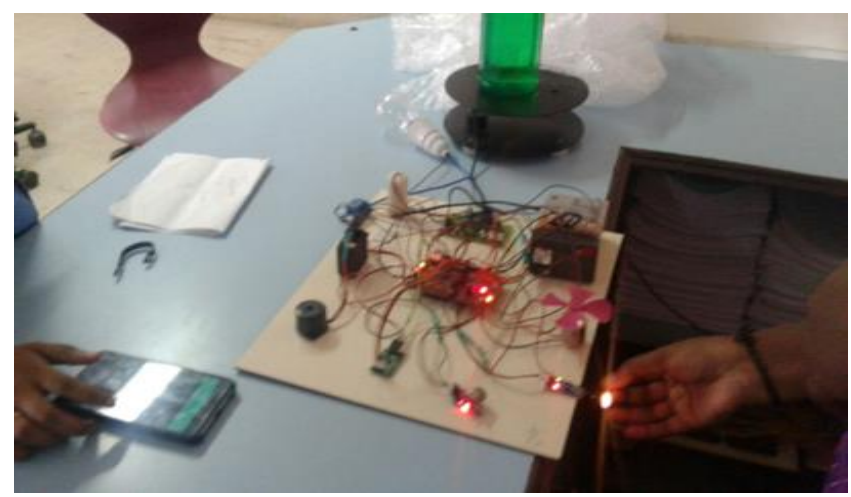

Figure 4. Firng sensing alert 


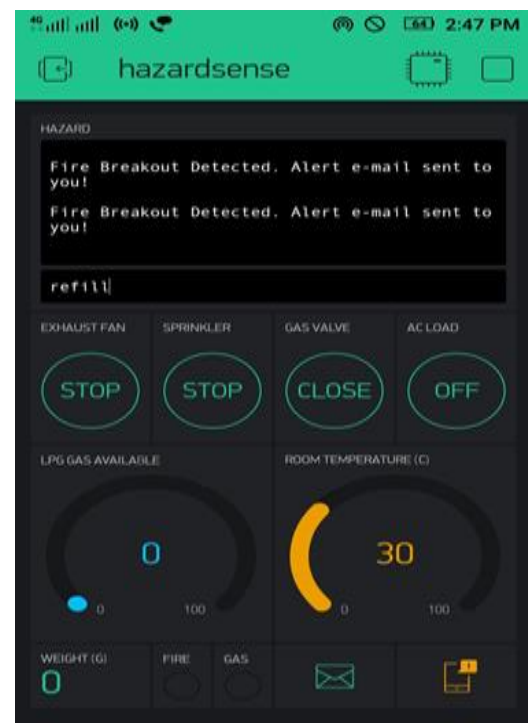

(a)

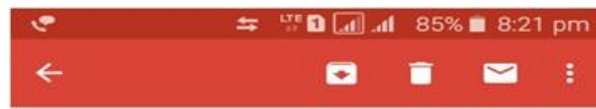

Subject: Hazard Sense Alert inbox t 하

D dispatcher@blynk.io Fire breakout has been detected.

9

D dispatcher@blynk.io me miew deteis

$\leftarrow \quad \vdots$

2 days ago View details

Fire breakout has been detected

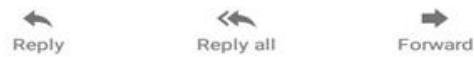

Figure 5. (a) Firng sensing alert, (b) Shows that the fire breakout has been detected by fire Sensor and intimated to owner through email

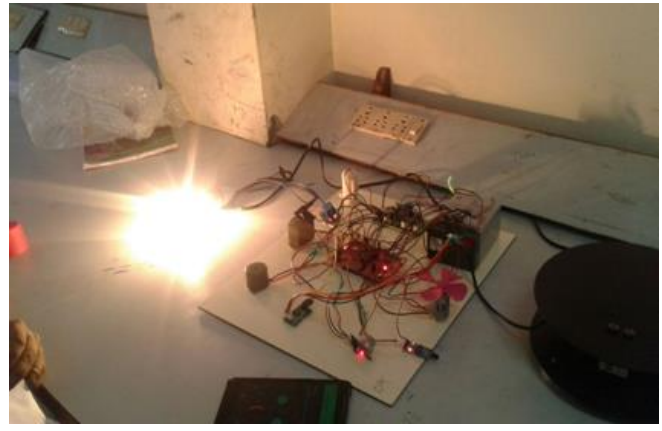

Figure 6. Before gas sense detection

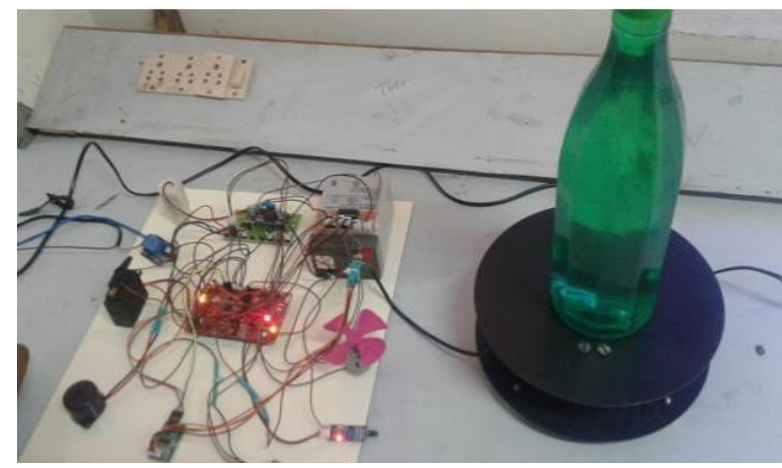

Figure 8. Weight sensing through load cell



Figure 7. After gas sense detection

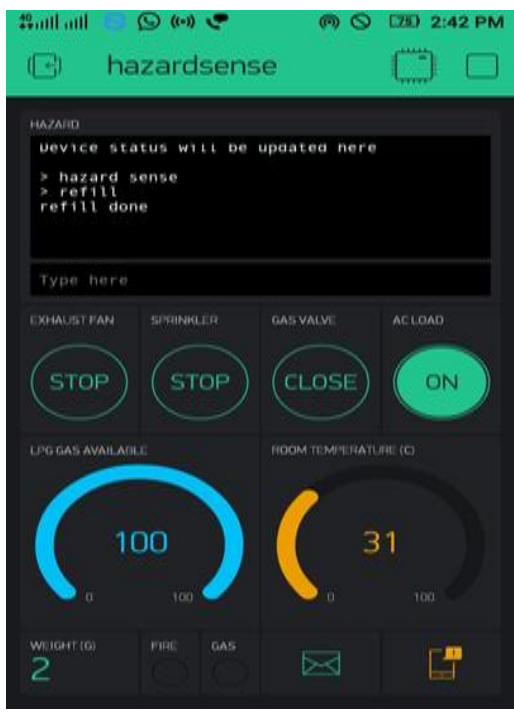

Figure 9. Notification of load in percentage from BLYNK application 


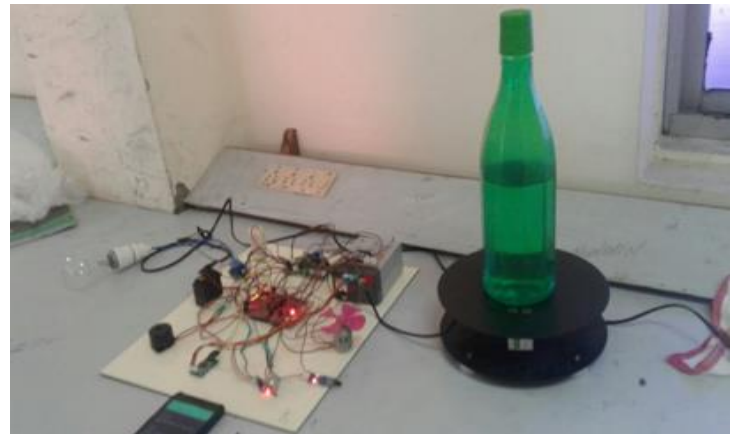

(a)

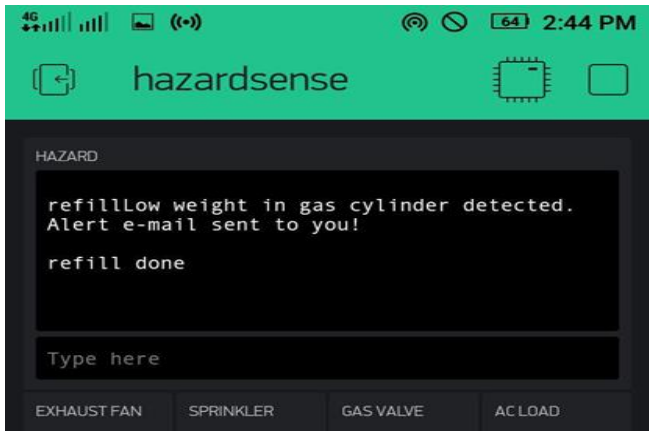

(b)

Figure 10. (a) and (b). Refilling of cylinder

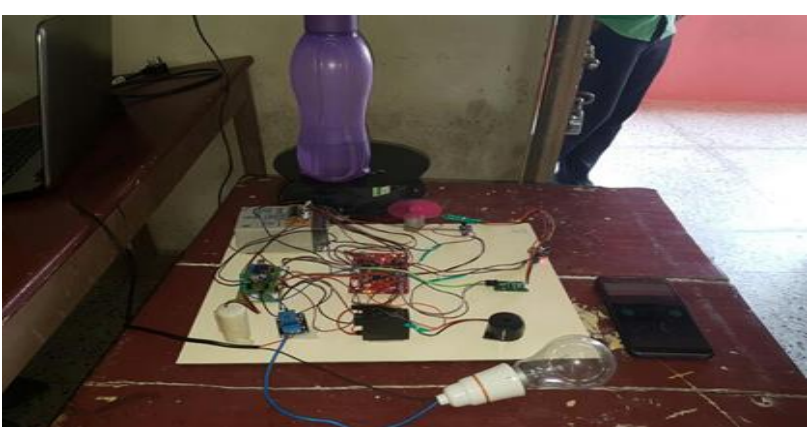

(a)

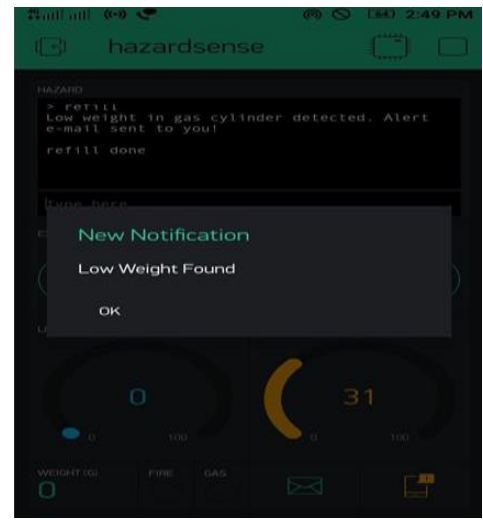

(b)

Figure 11. (a) and (b) Low weight alert

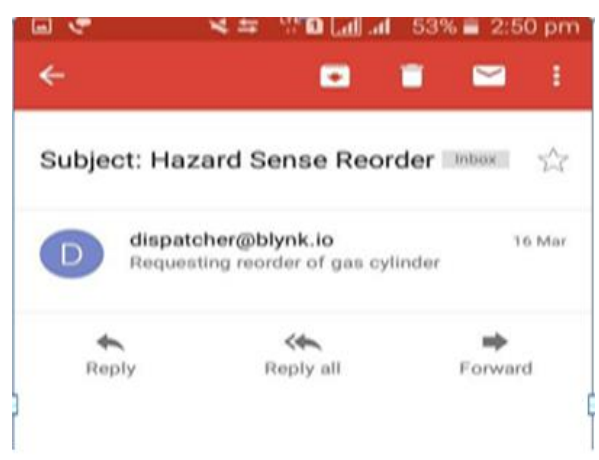

Figure 12. Reordering mail

The Figure1 represents the block diagram of the proposed work. Figure 2 showstheentirehardware kit oftheworkitconsistsofthevariouspartsthatresemblestheblock diagram. The hardware kit is connected through wifi. The cell phone displays the acts as front end. Through the cell phone the status the proposed work can be observed. Figure 3 givestheinitialconditionoftheproposedwork. Figure 4 discuss the fire alert. The fire is sensed through the fire sensor and the information is passes through the wifi and it is identified through the cell phone. The alert isgiven as messagetothecellphoneFigure 5 (a) and (b). Figure 6 (a) and (b) displaythe gas beforeandafter gas sensing. Figure 8 gives the load cell operation.

The load cell detects the weight of cylinder. Figure 9 display the weight of cylinder through BYLNK application. Figure 10 (a) and (b) shows the processes of refilling the cylinder. Figure 11 (a) and (b) gives the idea and information about low weight detection and its corresponding alert. Then the Figure 12 represents the reordering mail whenthe cylinder is empty. 


\section{CONCLUSION}

The proposed work was developed through hardware setup. The stepup was working effectively. It identifies the gas leakage and usage of gas information dead line to change the cylinder. The above details are controlled through online through mobile phone. The real time data and informations are strored in cloud for further retrival of information in future. Based on weight of the cylinder the amount of gas availibale and due date to change new cylinder may also be known. The informations are obtained through SMS from cloud storage.

\section{REFERENCES}

[1] V. Babuprasanth, "Cloud connected smart gas leakage detection,"International journal of MC square scientific research, vol. 6(1), pp. 18-24, 2014.

[2] H. Ruqsar, R. Chandana, R. Nandini and T. Surekha, "Internet of things ( Iot ) based real time gas leakage monitoring and controlling," Int. J. Electron. Commun. Eng. Technology, vol. 5(8), pp. 208-214, 2014.

[3] Shopan dey, Ayon roy, Sandip dap, "Home automation using internet of thing,"IEEE Annual Ubiquitous Computing, Electronics \& Mobile Communication Conference (UEMCON), 2016.

[4] G. V. Tawale-patil, K. H. Kulkarni, P. U. Kuwad and P. R. Pawar," Smart kitchen using IoT," International Journal of Research in advent technology, pp. 205-207, 2016.

[5] Pooja, D., Neha., Reddy, SRN., "IoT based home alert system using Wi-Fi and cloud technologies, "National conference on product design, pp. 1-6, 2016.

[6] B.V. Santhosh Krishna, J.Oviya, S.Gowri, M. Varshini, "Cloud robotics in industry using raspberry pi.," Science Technology Engineering and Management (ICONSTEM), 2016.

[7] K.Ayyar, M. Aishwarya, S. Anudharshane, A.V.R. Laxmipriya, M. Nikita, "Cloud connected LPG cylinder," Transactions on engineering and science, vol. 5(1), pp. 15-20, 2017.

[8] S. Anandhakrishnan, D. Nair, K. Rakesh, K. Sampath and G. S. Nair, "IOT based smart gas monitoring system," IOSR journal of electrical and electronics engineering, pp. 82-87, 2017.

[9] Swedika Sharma, "A state of art on energy efficient multipath routing in wireless sensor networks," International Journal of Informatics and Communication Technology (IJ-ICT), vol. 7(3), pp. 111-116, 2019.

[10] Vibha Raj Nag, M. Sarvagya, "Review paper on different dual band printed slot antenna for 5G wireless communication," International Journal of Informatics and Communication Technology (IJ-ICT), vol. 7(3), pp. 105-110, 2018.

[11] D. S. Marotkar, P.L. Zade, "Microstrip antenna with photographic paper substrate for WLAN," International Journal of Informatics and Communication Technology (IJ-ICT), vol. 7(2), pp. 67-70, 2018. 